\title{
Inflammatory Bowel Disease: A Personalized Approach
}

\author{
Anastasia Konidari $^{1,2 *}$, David Dickens ${ }^{2}$ and Munir Pirmohamed ${ }^{2}$ \\ ${ }^{1}$ B Pediatric Clinic, Paidon Aglaia Kyriakou Children's Hospital, Athens, Greece, ${ }^{2}$ The Wolfson Centre for Personalized \\ Medicine, Institute of Systems, Molecular and Integrative Biology (ISMIB), University of Liverpool, Liverpool, United Kingdom
}

Keywords: inflammatory bowel disease, personalized medicine, therapeutics, genetic susceptibility, childhood

\section{INTRODUCTION}

Inflammatory bowel disease (IBD) encompasses three major forms of chronic intestinal inflammation, including Crohn's disease (CD), ulcerative colitis (UC), and unclassified IBD (IBDU), previously known as indeterminate colitis. The definition of clinical phenotypes follows internationally agreed standards based on a constellation of clinical, endoscopic, radiologic, and histologic features. IBD is recognized as a heterogeneous spectrum of disorders with distinct clinical courses and symptom chronicity, which may present anytime from early childhood to adulthood (1-3). The burden of disease can be modified by treatment, but in principle, IBD presents with relapsing and remitting course throughout life (4). CD and UC, while sharing several similar pathologic and clinical features, have distinct differences in prognosis and management (5). Disease type and distribution in part influence disease progression and prognosis $(6,7)$.

Pediatric IBD is associated with greater disease burden and morbidity because it affects children at a critical period for growth and development. It is characterized by extensive and severe disease, which, if untreated, results in increased risk of intestinal strictures necessitating surgical treatment (8), growth failure, nutritional deficiencies, delayed puberty, metabolic bone disease, and increased risk of extra-intestinal manifestations such as hepatic, eye and skin disease, and psychiatric morbidity (9-11).

Andrew S. Day,

University of Otago, New Zealand

Reviewed by:

Madhur Ravikumara,

Perth Children's Hospital, Australia

*Correspondence:

Anastasia Konidari

anastasia.konidari@aglaiakyriakou.gr

Specialty section: This article was submitted to Pediatric Gastroenterology, Hepatology and Nutrition, a section of the journal

Frontiers in Pediatrics

Received: 23 October 2020 Accepted: 30 December 2020 Published: 11 February 2021

Citation:

Konidari A, Dickens D and Pirmohamed M (2021) Inflammatory Bowel Disease: A Personalized Approach. Front. Pediatr. 8:620545.

doi: 10.3389/fped.2020.620545

\section{GENETIC SUSCEPTIBILITY}

IBD is a heterogeneous disorder with multifactorial etiology (12); mapping of the interaction between genetic and environmental factors may inform molecular classification of disease in the future $(13,14)$. Over the last decade, various studies have reported that multiple genomic loci increase genetic susceptibility to IBD (15). Genome-wide association (GWA) and other studies have demonstrated how genetics can be applied for phenotype stratification $(16,17)$; such studies have provided an overview of relative contribution of various genomic loci to a number of human diseases including IBD, through genotyping of a large number of single-nucleotide polymorphisms (SNPs) across the human genome (18).

More than 163 IBD susceptibility genetic loci have been found in cohorts of European descent (19), with emerging data of how genetic variation can determine disease distribution (20). Of these loci, 110 confer risk to both IBD subtypes, whereas 30 and 23 loci are unique to CD and UC, respectively. The 163 loci explain $13.6 \%$ of $\mathrm{CD}$ and $7.5 \%$ of $\mathrm{UC}$ total disease variance, respectively (19). Liu et al. (21) have conducted the first trans-ethnic association study in IBD with use of GWA. Immunochip data from 86,640 Europeans and 9,846 subjects of Asian descent revealed additional 38 IBD susceptibility loci; the majority show similar direction and magnitude of effect between European and non-European populations (21).

Susceptibility genes encode proteins such as the nucleotide-binding oligomerization domain protein 2 (NOD2) with mutations affecting nuclear factor-kappa beta (NFKB) production, 
autophagy-related 16-like protein 1 (ATG16L1), immunityrelated GTPase family $M$ (IRGM), functional toll-like receptors (TLRs) (22), signal transducer and activation of transcription 3 (STAT3) protein, and interleukin 23 receptor (IL-23R) (23). Epigenetic alterations, such as DNA methylation, may further influence disease progression (24).

\section{CHILDHOOD-ONSET INFLAMMATORY BOWEL DISEASE}

IBD incidence and prevalence in children are increasing (25). National cohort studies have been included in a recent systematic review, which has confirmed the rising global trend of pediatric IBD in both developed and developing countries (26). Emerging evidence supports the need for a "top-down" approach in the implementation of treatment modalities, especially in children $(27,28)$. Furthermore, population-based cohort studies showed twice the risk of developing corticosteroid (CS) dependency within the first year from diagnosis in children, when compared with adults (29). Early poor response to treatment and severe disease extent at diagnosis as predictors of colectomy in pediatric UC further support the need for early initiation of patienttailored treatment.

Until fairly recently, there has been a paucity of studies about genes predisposing to childhood-onset IBD. A pediatric GWA study by Cutler et al. (30) in 1,008 pediatric-onset IBD patients and 1,633 controls confirmed overlap with common adult IBD susceptibility loci such as NOD2 and IL23R. Denson et al. (31) reported the results of whole-exome sequencing (WES) in 543 children with IBD. Low/normal neutrophil intrinsic granulocyte macrophage colony-stimulating factor (GM-CSF) signaling was found to be associated with colony-stimulating factor 2 receptor A subunit (CSF2RA) missense mutations, where neutrophils from IBD patients exhibited alterations in gene expression regulating cytokine production, wound healing, cell survival, and proliferation (31). The same group performed WES in children with IBD and healthy controls to identify mutations in genes encoding nicotinamide adenine dinucleotide phosphate oxidase (NADPH), and neutrophil gene expression associated with reactive oxygen species production. Patients with specific mutations in NADPH oxidases had more aggressive disease course in CD (31).

Very-early-onset IBD (VEO-IBD) presents below 6 years of age and manifests with a distinct phenotype, however, it is not predominantly a monogenic condition; next-generation sequencing such as WES or whole-genome screening (WGS) may help establish the molecular diagnosis to some extent, with a reported diagnostic yield varying between 13 and $26.5 \%$ (32), allowing for patient-specific early intervention the opportunity to screen family members for carrier detection and genetic counseling. IBD-like monogenic disorders are related to primary immunodeficiency, for example, defects of $\mathrm{T}$ and $\mathrm{B}$ lymphocyte selection and activation, disorders affecting regulatory $\mathrm{T}$ cell activity, and interleukin 10 (IL10) and IL10 receptor A/B (IL10R) A/B signaling (33). Other monogenic conditions include dysfunction of NADPH oxidase complex,
X-linked inhibitor of apoptosis (XIAP), lipopolysaccharide responsive beige-like anchor protein (LRBA), cytotoxic $\mathrm{T}$ lymphocyte-associated protein 4 (CTLA-4), STAT3, and chronic granulomatous disease (34). Mutations in the epithelial cell adhesion molecule (EPCAM), myosin Vb (MYO5B), Fork head Box P3 gene (FOXBP3), Tetratricopeptide Repeat Domain 37 (TTC37) (35), and the "immune dysregulation, polyendocrinopathy, enteropathy, X-linked” syndrome (36) have also been implicated in VEO-IBD. Tumor necrosis factor alpha-induced protein 3 (TNFAIP3) mutations cause infantileonset IBD (37). Monogenic IBD is also caused by genes related to intestinal epithelial defects, such as intestinal epithelial cell adhesion and generation of reactive oxygen species (38).

\section{MODERN TREATMENT PARADIGMS}

Therapeutic approaches involve potent inhibition of inflammatory pathways and immune suppression. Complicated disease course is largely associated with choice of treatment agents, drug efficacy, and sustained treatment response or lack of it. Medications are therefore not universally effective and can be associated with significant toxicity (39).

Individual carriers of risk allele HLA DRB1 03:01 for instance have been shown to be at 3-fold risk of 5ASA-related nephrotoxicity (40).

Next-generation sequencing performed in leucocytes of children with IBD at diagnosis and 4 weeks following introduction of CS showed significantly altered expression of 18 micro-RNAs; three of these micro-RNAs contained glucocorticoid-responsive elements in their gene promoters and could be putatively directly regulated by the GC receptor, while others recognized $3^{\prime}$ untranslated region of the GR gene (41).

Thiopurine drug monitoring is a successful paradigm of personalized treatment. Thiopurine methyltransferase (TPMT) genotyping is undertaken routinely prior to thiopurine introduction in patients with IBD (42). Patient response to treatment exhibits inter-individual variability thought to result from variation in drug metabolism $(43,44)$. TPMT genotype and activity can partially explain the variability in patient response. Hematological toxicity, commonly manifesting as leukopenia, is associated with the homozygous recessive TPMT genotype and intermediate/low TPMT activity. Optimal 6TGN level is a surrogate marker of response to thiopurine treatment; low metabolite concentration is indicative of poor compliance (45). $6 \mathrm{MMPR}$ monitoring can be useful for early identification of liver toxicity (43).

NUDT15 exon mutations have been associated with thiopurine-induced leucopenia in Asian patients (46). Sutiman et al. (47) have reported higher risk of thiopurine-induced myelotoxicity in Asian patients with IBD. The Clinical Pharmacogenetics Implementation Consortium has published guidance on thiopurine dosing recommendations based on TPMT and NUDT15 genotypes (48). Thiopurine-induced pancreatitis has been related to HLA DQA1-HLA DRB1 homozygous haplotypes; however, this association has not 
been yet included in routine pre-treatment pharmacogenetic panels (49).

There is emerging evidence about benefits of early antiTNF alpha administration (“top-down approach") for early disease remission, avoidance of later progression to stricturing/penetrating disease in $\mathrm{CD}$, improved quality of life, and reduction of hospital admission rates (50, 51). Primary loss of response to anti-TNF alpha occurs in up to a third of patients, with up to half of the patients losing response over time (52). There is preliminary evidence of HLA DQA $1^{*} 05$ haplotype association with 2 -fold increase of anti-TNF alpha immunogenicity risk (53). The association of drug levels and antibodies in relation to clinical outcomes requires further investigation; however, recent systematic review and metaanalysis overall support the finding that regular therapeutic drug monitoring contributes to avoidance of higher disease relapse rate (54).

Consideration of variable efflux transporter expression associated with common genetic polymorphisms may also influence response to treatment (55). Clinical response to CS treatment for instance could be influenced by $\mathrm{ABCB} 1$ interindividual expression variability on the basis that CSs are $\mathrm{ABCB} 1$ substrates (56).

\section{DISCUSSION}

IBD patients cannot be treated with "one size fits all” approach, because poor treatment response, adverse drug reactions, and therapeutic failure result in increasing morbidity and healthcare costs (57). Loss of response or severe refractory disease remains the main challenges that clinicians and patients face during the disease course. Safety profile concerns such as organ toxicity, accumulated cancer risk, and drug interactions also influence clinician and patient choices. Best clinical outcome with fewer drug-related adverse reactions result in

\section{REFERENCES}

1. Castellaneta SP, Afzal NA, Greenberg M, Deere H, Davies S, Murch SH, et al. Diagnostic role of upper gastrointestinal endoscopy in pediatric inflammatory bowel disease. J Pediatr Gastroenterol Nutr. (2004) 39:257-61. doi: 10.1097/00005176-200409000-00006

2. Actis GC, Rosina F, Mackay IR. Inflammatory bowel disease: beyond the boundaries of the bowel. Expert Rev Gastroent. (2011) 5:401-10. doi: 10.1586/egh.11.23

3. Horjus Talabur Horje CS, Meijer J, Rovers L, van Lochem EG, Groenen MJ, Wahab PJ. Prevalence of upper gastrointestinal lesions at primary diagnosis in adults with inflammatory bowel disease. Inflamm Bowel Dis. (2016) 22:1896-901. doi: 10.1097/MIB.00000000000 00786

4. Silverberg MS, Satsangi J, Ahmad T, Arnott ID, Bernstein CN, Brant SR, et al. Toward an integrated clinical, molecular and serological classification of inflammatory bowel disease: report of a Working Party of the 2005 Montreal World Congress of Gastroenterology. Can J Gastroenterol. (2005) 19(Suppl. A):5A-36A. doi: 10.1155/2005/269076

5. Guariso G, Gasparetto M. Treating children with inflammatory bowel disease: current and new perspectives. World J Gastroenterol. (2017) 23:5469-85. doi: 10.3748/wjg.v23.i30.5469 improved patient outcomes and optimal resource utilization; these goals are at the heart of personalized medicine. Research in patient-centered therapies based on the understanding of disease pathogenesis, genetic susceptibility, and inter-individual variability to treatment is ongoing $(58,59)$. The importance of personalized treatment in children is indicated by recent studies in childhood-onset $\mathrm{CD}$, which have shown that non-sustained response to treatment may be more important in predicting disease relapse and overall complications than actual disease severity and extent at diagnosis (60).

Research that involves large international consortia of rigorously characterized patients is therefore paramount in order to identify and validate clinically meaningful and applicable biomarkers. This research requires large patient numbers of different ethnicities for identification of common and rare allele variants, with emphasis on genotype/phenotype characterization and monitoring of disease progression and treatment response. Cost issues pose further challenges in this endeavor. The next frontier in IBD therapeutics is about implementation of translational pharmacogenetic associations in treatment algorithms, in order to tailor pharmacotherapy to individual patient profiles (61).

\section{AUTHOR CONTRIBUTIONS}

AK: conceptualization, interpretation of data, and writing of original draft. DD and MP: manuscript reviewing and editing. All authors contributed to the article and approved the submitted version.

\section{ACKNOWLEDGMENTS}

The manuscript content has formed part of a doctoral thesis submitted at the University of Liverpool, 2020, by AK.

6. Roussomoustakaki M, Satsangi J, Welsh K, Louis E, Fanning G, Targan S, et al. Genetic markers may predict disease behavior in patients with ulcerative colitis. Gastroenterology. (1997) 112:1845-53. doi: 10.1053/gast.1997.v112.pm9178675

7. Ho GT, Chiam P, Drummond H, Loane J, Arnott ID, Satsangi J. The efficacy of corticosteroid therapy in inflammatory bowel disease: analysis of a 5-year UK inception cohort. Aliment Pharmacol Ther. (2006) 24:319-30. doi: 10.1111/j.1365-2036.2006.02974.x

8. Schoepfer A, Santos J, Fournier N, Schibli S, Spalinger J, Vavricka S, et al. Systematic analysis of the impact of diagnostic delay on bowel damage in paediatric vs. adult onset crohn's disease. J Crohns Colitis. (2019) 13:1334-42. doi: 10.1093/ecco-jcc/jjz065

9. Butwicka A, Olen O, Larsson H, Halfvarson J, Almqvist C, Lichtenstein P, et al. Association of childhood-onset inflammatory bowel disease with risk of psychiatric disorders and suicide attempt. JAMA Pediatr. (2019) 173:969-78. doi: 10.1001/jamapediatrics.2019.2662

10. Mahfouz M, Martin P, Carrion AF. Hepatic complications of inflammatory bowel disease. Clin Liver Dis. (2019) 23:191-208. doi: 10.1016/j.cld.2018.12.003

11. Annese V. A review of extraintestinal manifestations and complications of inflammatory bowel disease. Saudi J Med Med Sci. (2019) 7:66-73. doi: 10.4103/sjmms.sjmms_81_18 
12. Morgan XC, Tickle TL, Sokol H, Gevers D, Devaney KL, Ward DV, et al. Dysfunction of the intestinal microbiome in inflammatory bowel disease and treatment. Genome Biol. (2012) 13:R79. doi: 10.1186/gb-2012-13-9-r79

13. Khor B, Gardet A, Xavier RJ. Genetics and pathogenesis of inflammatory bowel disease. Nature. (2011) 474:307-17. doi: 10.1038/nature10209

14. Lane ER, Zisman TL, Suskind DL. The microbiota in inflammatory bowel disease: current and therapeutic insights. J Inflamm Res. (2017) 10:63-73. doi: $10.2147 /$ JIR.S116088

15. Senhaji N, Kassogue Y, Fahimi M, Serbati N, Badre W, Nadifi S. Genetic polymorphisms of multidrug resistance gene-1 (MDR1/ABCB1) and glutathione s-transferase gene and the risk of inflammatory bowel disease among moroccan patients. Mediators Inflamm. (2015) 2015:248060. doi: $10.1155 / 2015 / 248060$

16. Haritunians T, Taylor KD, Targan SR, Dubinsky M, Ippoliti A, Kwon S, et al. Genetic predictors of medically refractory ulcerative colitis. Inflamm Bowel Dis. (2010) 16:1830-40. doi: 10.1002/ibd.21293

17. Plevy S, Silverberg MS, Lockton S, Stockfisch T, Croner L, Stachelski J, et al. Combined serological, genetic, and inflammatory markers differentiate non-IBD, Crohn's disease, and ulcerative colitis patients. Inflamm Bowel Dis. (2013) 19:1139-48. doi: 10.1097/MIB.0b013e318280b19e

18. Goldstein DB, Cavalleri GL. Genomics: understanding human diversity. Nature. (2005) 437:1241-2. doi: 10.1038/4371241a

19. Jostins L, Ripke S, Weersma RK, Duerr RH, McGovern DP, Hui $\mathrm{KY}$, et al. Host-microbe interactions have shaped the genetic architecture of inflammatory bowel disease. Nature. (2012) 491:119-24. doi: $10.1038 /$ nature 11582

20. Cleynen I, Boucher G, Jostins L, Schumm LP, Zeissig S, Ahmad T, et al. Inherited determinants of Crohn's disease and ulcerative colitis phenotypes: a genetic association study. Lancet. (2015) 387:156-67. doi: 10.1016/S0140-6736(15)00465-1

21. Liu JZ, van Sommeren S, Huang H, Ng SC, Alberts R, Takahashi A, et al. Association analyses identify 38 susceptibility loci for inflammatory bowel disease and highlight shared genetic risk across populations. Nat Genet. (2015) 47:979-86. doi: 10.1038/ng.3359

22. Torok HP, Bellon V, Konrad A, Lacher M, Tonenchi L, Siebeck M, et al. Functional toll-like receptor (TLR)2 polymorphisms in the susceptibility to inflammatory bowel disease. PLoS ONE. (2017) 12:e0175180. doi: 10.1371/journal.pone.0175180

23. Duerr RH, Taylor KD, Brant SR, Rioux JD, Silverberg MS, Daly MJ, et al. A genome-wide association study identifies IL23R as an inflammatory bowel disease gene. Science. (2006) 314:1461-3. doi: 10.1126/science.1135245

24. Harris RA, Shah R, Hollister EB, Tronstad RR, Hovdenak N, Szigeti R, et al. Colonic mucosal epigenome and microbiome development in children and adolescents. J Immunol Res. (2016) 2016:9170162. doi: 10.1155/2016/9170162

25. Henderson P, Wilson DC. The rising incidence of paediatriconset inflammatory bowel disease. Arch Dis Child. (2012) 97:585-6. doi: 10.1136/archdischild-2012-302018

26. Benchimol EI, Guttmann A, Griffiths AM, Rabeneck L, Mack DR, Brill H, et al. Increasing incidence of paediatric inflammatory bowel disease in Ontario, Canada: evidence from health administrative data. Gut. (2009) 58:1490-7. doi: 10.1136/gut.2009.188383

27. Duricova D, Burisch J, Jess T, Gower-Rousseau C, Lakatos PL, EpiCom E. Age-related differences in presentation and course of inflammatory bowel disease: an update on the population-based literature. J Crohns Colitis. (2014) 8:1351-61. doi: 10.1016/j.crohns.2014.05.006

28. Walters TD, Kim MO, Denson LA, Griffiths AM, Dubinsky M, Markowitz $\mathrm{J}$, et al. Increased effectiveness of early therapy with anti-tumor necrosis factor-alpha vs an immunomodulator in children with Crohn's disease. Gastroenterology. (2014) 146:383-91. doi: 10.1053/j.gastro.2013. 10.027

29. Duricova D, Pedersen N, Lenicek M, Jakobsen C, Lukas M, Wewer V, et al. The clinical implication of drug dependency in children and adults with inflammatory bowel disease: a review. J Crohns Colitis. (2011) 5:81-90. doi: 10.1016/j.crohns.2010.12.006

30. Cutler DJ, Zwick ME, Okou DT, Prahalad S, Walters T, Guthery SL, et al. Dissecting allele architecture of early onset IBD using high-density genotyping. PLoS ONE. (2015) 10:e0128074. doi: 10.1371/journal.pone.0128074
31. Denson LA, Jurickova I, Karns R, Shaw KA, Cutler DJ, Okou DT, et al. Clinical and genomic correlates of neutrophil reactive oxygen species production in pediatric patients with crohn's disease. Gastroenterology. (2018) 154:2097110. doi: 10.1053/j.gastro.2018.02.016

32. Lega S, Pin A, Arrigo S, Cifaldi C, Girardelli M, Bianco AM, et al. Diagnostic approach to monogenic inflammatory bowel disease in clinical practice: a ten-year multicentric experience. Inflamm Bowel Dis. (2020) 26:720-7. doi: 10.1093/ibd/izz178

33. Moran CJ, Walters TD, Guo CH, Kugathasan S, Klein C, Turner D, et al. IL-10R polymorphisms are associated with very-early-onset ulcerative colitis. Inflamm Bowel Dis. (2013) 19:115-23. doi: 10.1002/ibd.22974

34. Shouval DS, Rufo PA. The role of environmental factors in the pathogenesis of inflammatory bowel diseases: a review. JAMA Pediatr. (2017) 171:999-1005. doi: 10.1001/jamapediatrics.2017.2571

35. Fabre A, Breton A, Coste ME, Colomb V, Dubern B, Lachaux $A$, et al. Syndromic (phenotypic) diarrhoea of infancy/trichohepato-enteric syndrome. Arch Dis Child. (2014) 99:35-8. doi: 10.1136/archdischild-2013-304016

36. Charbit-Henrion F, Parlato M, Hanein S, Duclaux-Loras R, Nowak J, Begue $\mathrm{B}$, et al. Diagnostic yield of next-generation sequencing in very early-onset inflammatory bowel diseases: a multicentre study. J Crohns Colitis. (2018) 12:1104-12. doi: 10.1093/ecco-jcc/jjy068

37. Zheng C, Huang Y, Ye Z, Wang Y, Tang Z, Lu J, et al. Infantile onset intractable inflammatory bowel disease due to novel heterozygous mutations in TNFAIP3 (A20). Inflamm Bowel Dis. (2018) 24:2613-20. doi: 10.1093/ibd/izy165

38. Leung G, Muise AM. Monogenic intestinal epithelium defects and the development of inflammatory bowel disease. Physiology. (2018) 33:360-9. doi: 10.1152/physiol.00020.2018

39. Colombel JF, Reinisch W, Mantzaris GJ, Kornbluth A, Rutgeerts P, Tang $\mathrm{KL}$, et al. Randomised clinical trial: deep remission in biologic and immunomodulator naive patients with crohn's disease - a SONIC post hoc analysis. Aliment Pharmacol Ther. (2015) 41:734-46. doi: 10.1111/apt.13139

40. Heap GA, So K, Weedon M, Edney N, Bewshea C, Singh A, et al. Clinical Features and HLA association of 5-Aminosalicylate (5-ASA)-induced nephrotoxicity in inflammatory bowel disease. J Crohns Colitis. (2016) 10:149-58. doi: 10.1093/ecco-jcc/jjv219

41. De Iudicibus S, Lucafo M, Vitulo N, Martelossi S, Zimbello R, De Pascale F, et al. High-throughput sequencing of microRNAs in glucocorticoid sensitive paediatric inflammatory bowel disease patients. Int J Mol Sci. (2018) 19:1399. doi: 10.3390/ijms19051399

42. Liu YP, Xu HQ, Li M, Yang X, Yu S, Fu WL, et al. Association between thiopurine S-methyltransferase polymorphisms and azathioprine-induced adverse drug reactions in patients with autoimmune diseases: a meta-analysis. PLoS ONE. (2015) 10:e0144234. doi: 10.1145/2818302

43. Konidari A, Anagnostopoulos A, Bonnett LJ, Pirmohamed M, ElMatary W. Thiopurine monitoring in children with inflammatory bowel disease: a systematic review. Brit J Clin Pharmaco. (2014) 78:467-76. doi: $10.1111 /$ bcp. 12365

44. Lennard L, Cartwright CS, Wade R, Vora A. Thiopurine dose intensity and treatment outcome in childhood lymphoblastic leukaemia: the influence of thiopurine methyltransferase pharmacogenetics. Br J Haematol. (2015) 169:228-40. doi: 10.1111/bjh.13240

45. Relling MV, Gardner EE, Sandborn WJ, Schmiegelow K, Pui CH, Yee SW, et al. Clinical pharmacogenetics implementation consortium guidelines for thiopurine methyltransferase genotype and thiopurine dosing: 2013 update. Clin Pharmacol Ther. (2013) 93:324-5. doi: 10.1038/clpt.2013.4

46. Kojima Y, Hirotsu Y, Omata W, Sugimori M, Takaoka S, Ashizawa H, et al. Influence of NUDT15 variants on hematological pictures of patients with inflammatory bowel disease treated with thiopurines. World J Gastroenterol. (2018) 24:511-8. doi: 10.3748/wjg.v24.i4.511

47. Sutiman N, Chen S, Ling KL, Chuah SW, Leong WF, Nadiger V, et al. Predictive role of NUDT15 variants on thiopurine-induced myelotoxicity in Asian inflammatory bowel disease patients. Pharmacogenomics. (2018) 19:31-43. doi: 10.2217/pgs-2017-0147

48. Relling MV, Schwab M, Whirl-Carrillo M, Suarez-Kurtz G, Pui CH, Stein $\mathrm{CM}$, et al. Clinical pharmacogenetics implementation consortium guideline for thiopurine dosing based on TPMT and NUDT15 genotypes: 2018 Update. Clin Pharmacol Ther. (2019) 105:1095-105. doi: 10.1002/cpt.1304 
49. Heap GA, Weedon MN, Bewshea CM, Singh A, Chen M, Satchwell JB, et al. HLA-DQA1-HLA-DRB1 variants confer susceptibility to pancreatitis induced by thiopurine immunosuppressants. Nat Genet. (2014) 46:1131-4. doi: 10.1038/ng.3093

50. Roda G, Jharap B, Neeraj N, Colombel JF. Loss of response to anti-TNFs: definition, epidemiology, and management. Clin Transl Gastroen. (2016) 7:e135. doi: 10.1038/ctg.2015.63

51. Kerur B, Machan JT, Shapiro JM, Cerezo CS, Markowitz J, Mack DR, et al. Biologics delay progression of crohn's disease, but not early surgery, in children. Clin Gastroenterol Hepatol. (2018) 16:1467-73. doi: 10.1016/j.cgh.2018.02.027

52. Scaldaferri F, D’Ambrosio D, Holleran G, Poscia A, Petito V, Lopetuso L, et al. Body mass index influences infliximab post-infusion levels and correlates with prospective loss of response to the drug in a cohort of inflammatory bowel disease patients under maintenance therapy with Infliximab. PLoS ONE. (2017) 12:e0186575. doi: 10.1371/journal.pone.0186575

53. Sazonovs A, Barrett JC. Rare-variant studies to complement genome-wide association studies. Annu Rev Genomics Hum Genet. (2018) 19:97-112. doi: 10.1146/annurev-genom-083117-021641

54. Ricciuto A, Dhaliwal J, Walters TD, Griffiths AM, Church PC. Clinical outcomes with therapeutic drug monitoring in inflammatory bowel disease: a systematic review with meta-analysis. J Crohns Colitis. (2018) 12:1302-15. doi: 10.1093/ecco-jcc/jjy109

55. Russell RK, Wilson ML, Loganathan S, Bourke B, Kiparissi F, Mahdi G, et al. A British society of paediatric gastroenterology, hepatology and nutrition survey of the effectiveness and safety of adalimumab in children with inflammatory bowel disease. Aliment Pharmacol Ther. (2011) 33:946-53. doi: 10.1111/j.1365-2036.2011.04603.x

56. Ho GT, Gaya DR, Satsangi J. Multidrug resistance (MDR1) gene in inflammatory bowel disease: a key player? Inflamm Bowel Dis. (2005) 11:1013-9. doi: 10.1097/01.MIB.0000186488.53493.c3
57. Molodecky NA, Soon IS, Rabi DM, Ghali WA, Ferris M, Chernoff G, et al Increasing incidence and prevalence of the inflammatory bowel diseases with time, based on systematic review. Gastroenterology. (2012) 142:46-54.e42; quiz e30. doi: 10.1053/j.gastro.2011.10.001

58. Cascorbi I. Inflammation: treatment progress and limitations. Clin Pharmacol Ther. (2017) 102:564-7. doi: 10.1002/cpt.792

59. Timmer A, Stark R, Peplies J, Classen M, Laass MW, Koletzko S. Current health status and medical therapy of patients with pediatric-onset inflammatory bowel disease: a survey-based analysis on 1280 patients aged 10 25 years focusing on differences by age of onset. Eur J Gastroenterol Hepatol. (2017) 29:1276-83. doi: 10.1097/MEG.0000000000000956

60. Ziv-Baran T, Hussey S, Sladek M, Amil Dias J, Martin de Carpi J, Miele E, et al. Response to treatment is more important than disease severity at diagnosis for prediction of early relapse in new-onset paediatric Crohn's disease. Aliment Pharmacol Ther. (2018) 48:1242-50. doi: 10.1111/apt.15016

61. Voskuil MD, Bangma A, Weersma RK, Festen EAM. Predicting (side) effects for patients with inflammatory bowel disease: the promise of pharmacogenetics. World J Gastroenterol. (2019) 25:2539-48. doi: 10.3748/wjg.v25.i21.2539

Conflict of Interest: The authors declare that the research was conducted in the absence of any commercial or financial relationships that could be construed as a potential conflict of interest.

Copyright () 2021 Konidari, Dickens and Pirmohamed. This is an open-access article distributed under the terms of the Creative Commons Attribution License (CC BY). The use, distribution or reproduction in other forums is permitted, provided the original author(s) and the copyright owner(s) are credited and that the original publication in this journal is cited, in accordance with accepted academic practice. No use, distribution or reproduction is permitted which does not comply with these terms. 